\title{
Intra-varietal Agronomical Variability in Vitis vinifera L. cv. Cannonau Investigated by Fluorescence, Texture and Colorimetric Analysis
}

\author{
L. Mercenaro*, G. Usai, C. Fadda, G. Nieddu, A. del Caro \\ Department of Agriculture, Viticulture and Enology Research Group, University of Sassari, Via E. De Nicola 1, 07100 Sassari, \\ Italy
}

Submission for publication: November 2015

Accepted for publication: February 2016

Keywords: Biotypes, anthocyanins, CIELab, FERARI, skin thickness

\begin{abstract}
To date, innovative, rapid and non-invasive techniques have been used to assess variations in morphological and technological characteristics between grape cultivars. In order to improve knowledge of the qualitative expression of the genetic traits of cv. Cannonau (syn. Grenache), fluorescence, texture and colorimetric analyses were performed on 85 biotypes attributable to this variety. Eighty-five Cannonau biotypes cultivated in the same vineyard were analysed in order to evaluate their morphological and agronomical characteristics. As regards the morphological traits, of the six descriptors observed, five were able to discriminate the Cannonau population according to different expression levels. Must composition, berry colour (using the Minolta tristimulus colorimeter), texture (assessed using the TaxT2i plus texturimeter) and fluorescence (using the Multiplex III detector) were determined on clusters harvested at the same time. Cluster analysis was able to separate the Cannonau population into five groups, characterised by differences in the following criteria: $\mathrm{L}^{*}, \mathrm{a}^{*}$ and $\mathrm{b}^{*}$, berry skin thickness, FERARI, TSS, pH and titratable acidity, total polyphenols and total anthocyanins. The FERARI index was highly and positively correlated with total anthocyanins and negatively correlated with grape colour, while berry weight and berry skin thickness were not correlated with any variable assessed. The remarkable intra-variability encountered for the qualitative and quantitative characters in the Cannonau variety suggests that new biotypes could be selected for different oenological purposes, using techniques such as the measure of fluorescence and colorimetry. This is the first study carried out within the cv. Cannonau using innovative and classical techniques suitable to investigate intra-varietal variability.
\end{abstract}

\section{INTRODUCTION}

Natural biodiversity has played a leading role in the evolution of agriculture over the centuries, in terms of which crops were selected according to the identification, manipulation and domestication of wild species (Chessa \& Nieddu, 2005). Although a cultivar consists of vines presenting the same basic characteristics, there is remarkable genetic variability within each cultivar, resulting from the occurrence of spontaneous genetic mutations and their transmission to subsequent progeny (Mannini et al., 2011). Vegetative propagation helped to multiply and spread cultivars and clones around the world, further expanding intra-varietal variability. Numerous studies investigating the impact of clonal variability on the yield component and fruit composition of different grapevine varieties have been carried out since the late 1980s. Knowledge about intra-varietal variability is widely recognised in the wine industries. Indeed, understanding the agronomic and technological characteristics of the different clones and their wines has led to an increase in oenological products and improvements in wine quality. Differences among clones may relate to amphelographic characteristics and phenological phases (Nieddu et al., 2006), disease resistance (Van Leeuwen et al., 2012), yield and berry composition (Fidelibus et al., 2006; Anderson et al., 2008; Mercenaro et al., 2009), as well as secondary metabolite concentrations (Belancic \& Agosin, 2007; Mulas et al., 2011). However, the level of intra-varietal variability is also cultivar dependent. Some cultivars, such as Pinot noir and Chenin, show great variability, whereas others, such as Cabernet Sauvignon and Garnacha Tintorea, are more homogeneous (Boso et al., 2004). Another approach to studying the intravarietal variability in Vitis vinifera L. involves molecular techniques (Carimi et al., 2011). Meneghetti et al. (2011) studied 53 Garnacha (syn. Grenache) accessions coming from France, Spain and Italy using a PCR-derived marker system to characterise the clones. They confirmed that all accessions belonged to the same cultivar, yet the molecular marker system was clearly able to distinguish the Garnacha

*Corresponding author: E-mail address: mercenaro@uniss.it [Tel.: +39079 229336, fax: +39079 229339]

Acknowledgements: This work was performed within the project SQFVS (APQ P6) and carried out by the Convisar wineries: Argiolas, Serdiana; Cantina Gallura, Tempio; Cantina Li Duni, Badesi; Cantina delle Vigne di Piero Mancini, Olbia; Cantina del Mandrolisai, Sorgono; Cantina Trexenta, Senorbi 
accessions according to their area of origin. The authors revealed high levels of genetic similarity among the Spanish and French accessions, and high levels of genetic dissimilarity among the Italian accessions originating from different zones of cultivation (Alicante, Tocai Rosso, Gamay Perugino, Cannonau).

The Garnacha grapevine, covering 185000 hectares worldwide, is one of the most widely cultivated wine grapes in the world (Anderson, 2013). The European wine growers know it by different names, depending on their geographical origin: Garnacha Tinta and Grenache Noir are the Spanish and French names respectively, while in Italy this grape is known as Tocai Rosso (north-east regions), Alicante, Gamay Perugino (central regions) and Cannonau (on the island of Sardinia).

Anthocyanins, mainly contained within the grape skin, are the key compounds responsible for the colour of red grapes and of their wines; Cannonau is characterised, and can easily be distinguished from other cultivars, for it slow anthocyanin content and high percentage of malvidin, which accounts for about $66 \%$ of the colour fraction (Vacca et al., 2009; Fernandes de Oliveira et al., 2015).

An innovative non-invasive tool for testing grape phenolic maturity and for establishing the ideal harvest time is the portable fluorescence detector, the Multiplex (FORCE-A, Orsay, France) (Cerovic et al., 2008; Ghozlen et al., 2010a; 2010b). At present, to the best of our knowledge, only one study has dealt with the use of the Multiplex for determining colour differences among clones of table grapes (Bahar et al., 2012). The results of this study demonstrated the efficient use of this instrument for the analysis of grape quality.

Similarly, variability in grape skin colour can be assessed using the CIELab system by tristimulus colorimetry, allowing different varieties to be compared (Rolle \& Guidoni, 2007) and grape colour to be correlated with anthocyanin content (Liang et al., 2011).

Grape skin hardness, on the other hand, evaluated by the skin break force and skin break energy parameters, is a mechanical property, as is skin thickness, considered appropriate for the estimation of skin cell wall degradability and, therefore, for the extractability of anthocyanins from the berry skins into the must/wine (Río Segade et al., 2008; Rolle et al., 2011).

To date, neither the fluorescence technique using the Multiplex nor colour evaluation using CIELAB have been used to discriminate biotypes within the same wine grape variety. The purpose of this manuscript was to evaluate the intravarietal level of variability of 85 biotypes of cv. Cannonau, selected during a previous massal genetic improvement programme. For this reason, agronomical measurements on vines chemical analyses on must, innovative techniques such as fluorescence, texture and colorimetric analysis on berries were used. All the biotypes, coming from different areas of Sardinia, were planted in the same vineyard and subjected to the same agronomical practices. The results of the combined application of the Multiplex portable fluorescence detector, the CIELab colorimetric system and instrumental texture analysis of wine grapes, are reported and discussed here.

\section{MATERIALS AND METHODS \\ Sampling}

The trial was conducted in an experimental vineyard planted in 2009 and located in the Parteolla Valley of Serdiana in south-west Sardinia, Italy. The soil is alluvial, homogeneous, and has an average depth of 80 to $100 \mathrm{~cm}$, with the following characteristics: sand $51 \%$, clay $24.9 \%$ and silt $24.1 \%$; it has a $\mathrm{pH}$ of 7.44 and the organic matter content is $16 \mathrm{~g} / \mathrm{Kg}$. The vineyard covers $2500 \mathrm{~m}^{2}$; a total of 103 biotypes of $\mathrm{cv}$. Cannonau (a.k.a. Grenache) are present in this plot, with 11 contiguous vines per each biotype. The vines were grafted onto $1103 \mathrm{P}$ rootstock and spaced $2.1 \mathrm{~m} \mathrm{x} 1.0 \mathrm{~m}$ apart. The plants were trained according to the vertical shoot position in a cane-pruned system with a total of eight buds per vine. For the scope of the present study, 85 biotypes were assessed. No cluster thinning was performed in order to evaluate the real yield and, consequently, the oenological potential of these biotypes. From the pea-size stage to veraison the vines received a total of three irrigations by means of a drip irrigation system (corresponding to about $700 \mathrm{~m}^{3} \mathrm{ha}^{-1}$ year ${ }^{-1}$ ). Weed control along the rows was performed using herbicide. The experiment started during the commercial harvest period, with all grapes being hand-picked on 2012-10-01. For each selection under observation, nine of 11 vines were harvested and the yields recorded for each plant. To define yield components, cluster and berry weights were recorded by weighing 18 clusters randomly chosen from each plot, at two clusters per vine, with 20 berries randomly chosen from each cluster. Practically, agronomical data for each selection were represented by the mean of 18 biological replications.

\section{Fruit composition}

For the assessment of the fruit composition, the nine vines were divided into three groups, each containing three contiguous vines. A total of $0.5 \mathrm{~kg}$ of berries, with pedicel, and randomly picked, were collected from each group. The berries were weighed and crushed and the juice was analysed for sugar content, expressed as total soluble solids (TSS) ( $\left.{ }^{\circ} \mathrm{Brix}\right), \mathrm{pH}$ and titratable acidity according to the methods of the Office International de la Vigne et du Vin (OIV, 1990). The amounts of total polyphenols and total anthocyanins were evaluated by spectrophotometry, according to Di Stefano and Cravero (1991), with ultraviolet absorption measured at $700 \mathrm{~nm}$ and $520 \mathrm{~nm}$. Chemical parameters were represented by the mean of the three biological replicates.

\section{Morphological data}

At the time of harvest, morphological data were collected for all selections using six primary descriptors from the OIV Grape Descriptor List (OIV, 2001). In particular, three descriptors described cluster characteristics: density (OIV code 204), shape (OIV code 208) and number of wings of the primary cluster (OIV code 209); and three descriptors identified berry characteristics: uniformity of size (OIV code 222), shape (OIV code 223) and skin colour (OIV code 225). During the dormant season, the weight of the pruning wood and the number of shoots per vine were recorded in order to estimate vegetative growth. The weight of the pruning wood was also used to calculate the Ravaz Index (yield-topruning-weight ratio). 


\section{Colour analysis}

Ten berries per sample were analysed using a Minolta tristimulus colorimeter CR 300 (Osaka, Japan), with D65 as illuminant and a $2^{\circ}$ standard observer. CIELab space colour was used, where $\mathrm{L}^{*}$ indicates lightness, a* indicates red $(+a)$ to green $(-a)$ colours, and $b^{*}$ indicates yellow (+ b) to blue $(-b)$ colours. Hue angle $\left(\tan ^{-1} b^{*} / a^{*}\right)$ and chroma $\left(\mathrm{a}^{2}+\mathrm{b}^{2}\right)^{0.5}$ parameters were also calculated. The colorimeter was calibrated using a standard white plate.

\section{Fluorescence analysis}

The same berries were placed on a square dark tray with $6 \mathrm{~cm}$ sides and analysed using the portable fluorescence detector Multiplex III (Force A, Orsay, France) (Ghozlen et al., 2010a), as reported in the literature, where it was used to indicate the ripeness grade of table grapes (Bahar et al., 2012). Each berry was analysed twice on each side, thus obtaining four measurements per sample. The following parameters were determined: BRR FRF (blue to red fluorescence), FER_RUV (fluorescence excitation), FLAV (log of FER_RUV), FER_RG (fluorescence excitation ratio), FER_RB, ANTH_RG (log (FRF_R/FRF_G)), ANTH_RB and FERARI (log of FRF_R).

\section{Texture analysis}

Berries collected at harvest were frozen at $-20^{\circ} \mathrm{C}$ until analysis. In order to preserve the berry integrity, the samples were stored with the pedicel and subjected to fast-freezing to avoid the development of micro ice crystals that could interfere with the skin separation from the berry. Texture analysis was performed using a TaxT2i plus texturimeter (Stable Micro System, Surrey, UK) equipped with a HDP/90 platform and a load cell of $5 \mathrm{~kg}$, calibrated for $2 \mathrm{~kg}$ of force for berry skin thickness, and a load cell of $30 \mathrm{~kg}$, calibrated for $10 \mathrm{~kg}$ of force for seed deformation. Berry skin thickness was performed on 20 berries for each clone, using a small lancet and a clamp to separate a piece of skin from the lateral side of each berry. A sample of $0.25 \mathrm{~cm}^{-1}$ from each berry separated from the pulp was prepared as reported in RíoSegade et al. (2008). To evaluate berry skin thickness ( $\left.\mathrm{Sp}_{\mathrm{sk}}\right)$, an instrumental trigger threshold equal to $0.05 \mathrm{~N}$ was inserted to permit the plane surface probe to adhere to the skin sample before the acquisition started (Battista et al., 2015). Before starting the test, the instrument was calibrated for force and distance. The mechanical properties of seeds were evaluated as follows - seeds were withdrawn from 10 berries, dried with adsorbent paper and analysed for the following parameters: seed break force $\left(\mathrm{N}\right.$, as $\left.\mathrm{F}_{\mathrm{s}}\right)$ at the moment of compression (50\% deformation); seed break energy $\left(\mathrm{mJ}\right.$, as $\left.\mathrm{W}_{\mathrm{s}}\right)$; seed break distance $(\mathrm{mm})$; and seed deformation index $(\%$, as $\mathrm{DI}_{\mathrm{s}}$ ), calculated as previously reported (Letaief et al., 2008; Rolle et al., 2012). All the setting parameters are reported in Table 1.

\section{Statistical analysis}

The statistical analysis was performed using Statistica 6.0 for Windows (Statsoft). The multivariate statistical techniques used were principal component analysis, to investigate the relationships between the variables and the 85 biotypes, and cluster analysis, to identify clusters on the basis of similarities among the biotypes, using complete linkages between groups and the square Euclidean distance. Oneway Anova, followed by LSD Fisher's test, was applied to estimate significant differences among the groups obtained from the cluster analysis. Pearson's correlation was used to investigate the relationships between the measured parameters.

\section{RESULTS}

Regarding the ampelographic traits, only one descriptor was unable to discriminate the Cannonau population according to different expression levels: all biotypes were characterised by the OIV code number 223 berry shape, indicating an ellipsoid form. With reference to OIV code number 222 (Table 2), 92\% of the population exhibited berries with a uniform size, while only $8 \%$ of the biotypes showed nonuniform berry sizes. The berry skin colour descriptor, OIV code number 225, grouped the biotypes into four distinct expression levels. More specifically, visual analysis assigned $11 \%$ of the biotypes to a rose colour, $14 \%$ to a red colour, and $48 \%$ and $27 \%$ exhibited dark red violet and blue black skin colours respectively. With regard to the grape cluster descriptors, three levels of cluster density (OIV code number 204) were recorded. Forty-three biotypes were characterised as dense clusters, while 33 were catalogued as very dense clusters. Only nine biotypes were identified to be of medium cluster density. Regarding the cluster shape (OIV code number 208), the conical shape was detected most frequently. Cylindrical and funnel shaped clusters were found in 24 and 19 of the 85 biotypes respectively. Another descriptor used to discriminate between biotypes was the number of wings of the primary cluster (OIV code number 209). Of the 85 biotypes analysed, 70 presented one or two wings, 14 presented three or four wings, and wings were absent in just four biotypes. With regard to yield, biotype B46 exhibited the lowest production, at $0.99 \mathrm{~kg} /$ vine, while the highest production was recorded for $\mathrm{B} 10$, at $4.88 \mathrm{~kg} / \mathrm{vine}$. The average yield for the whole population was $2.39 \mathrm{~kg} / \mathrm{vine}$.

TABLE 1

Texture analysis settings for skin thickness and seed hardness determination using a TA.XT2i plus texturimeter.

\begin{tabular}{lllll}
\hline Test & Probe & Test speed & Deformation & Mechanical property \\
\hline Skin thickness & sms p2, $2 \mathrm{~mm}$ & $0.20 \mathrm{~mm} / \mathrm{sec}$ & - & Skin thickness $(\mu \mathrm{m})$ \\
& & & $\mathrm{F}_{\mathrm{s}}$ seed break force $(\mathrm{N})$ \\
& & & $\mathrm{W}_{\mathrm{s}}$ seed break energy $(\mathrm{mJ})$ \\
Seed hardness & sms p35, $\varnothing 35 \mathrm{~mm}$ & $1 \mathrm{~mm} / \mathrm{sec}$ & $50 \%$ & $\begin{array}{l}\text { Seed break distance }(\mathrm{mm}) \\
\text { Seed deformation index }(\%)\end{array}$ \\
\hline
\end{tabular}


TABLE 2

Ampelographic descriptor expression levels of the Cannonau biotypes. Cluster characteristics are related to density (OIV 204), shape (OIV 208) and number of wings of the primary cluster (OIV 209); berry characteristics are related to uniformity of size within the cluster (OIV 222) and skin colour (OIV 225).

\begin{tabular}{|c|c|c|c|c|c|}
\hline Biotypes & (OIV 204) & (OIV 208) & (OIV 209) & (OIV 222) & (OIV 225) \\
\hline BT 1 & medium & conical & $1-2$ wings & uniform & blue-black \\
\hline BT 2 & medium & conical & 1 - 2 wings & uniform & blue-black \\
\hline BT 3 & dense & conical & 3 - 4 wings & uniform & dark red-violet \\
\hline BT 4 & dense & cylindrical & 1 - 2 wings & uniform & rose \\
\hline BT 5 & dense & cylindrical & 1 - 2 wings & uniform & rose \\
\hline BT 6 & medium & conical & 1 - 2 wings & uniform & dark red-violet \\
\hline BТ 7 & dense & conical & 1 - 2 wings & uniform & red \\
\hline BT 8 & dense & funnel shaped & 1 - 2 wings & uniform & blue-black \\
\hline ВТ 9 & dense & funnel shaped & 1 - 2 wings & uniform & dark red-violet \\
\hline BT 10 & very dense & funnel shaped & $1-2$ wings & uniform & rose \\
\hline BT 11 & dense & conical & 1 - 2 wings & uniform & blue-black \\
\hline BT 12 & dense & cylindrical & 1 - 2 wings & uniform & dark red-violet \\
\hline BT 13 & very dense & funnel shaped & 1 - 2 wings & uniform & blue-black \\
\hline BT 14 & dense & conical & 3 - 4 wings & non uniform & red \\
\hline BT 15 & dense & conical & absent & uniform & dark red-violet \\
\hline BT 16 & dense & cylindrical & 1 - 2 wings & uniform & dark red-violet \\
\hline BT 17 & very dense & conical & 1 - 2 wings & uniform & red \\
\hline BT 18 & dense & conical & 3 - 4 wings & uniform & red \\
\hline BT 19 & dense & conical & 1 - 2 wings & uniform & rose \\
\hline BT 20 & dense & cylindrical & 1 - 2 wings & uniform & rose \\
\hline BT 21 & very dense & cylindrical & absent & uniform & rose \\
\hline BT 22 & dense & funnel shaped & $1-2$ wings & non uniform & blue-black \\
\hline BT 23 & dense & funnel shaped & 1 - 2 wings & non uniform & dark red-violet \\
\hline BT 24 & very dense & cylindrical & 1 - 2 wings & uniform & red \\
\hline BT 25 & dense & conical & 1 - 2 wings & uniform & red \\
\hline BT 26 & very dense & conical & 3 - 4 wings & uniform & dark red-violet \\
\hline BT 27 & dense & conical & 1 - 2 wings & non uniform & blue-black \\
\hline BT 28 & dense & conical & 1 - 2 wings & non uniform & rose \\
\hline BT 29 & dense & conical & 1 - 2 wings & uniform & red \\
\hline ВТ 30 & dense & cylindrical & 1 - 2 wings & non uniform & red \\
\hline BT 31 & dense & cylindrical & $3-4$ wings & uniform & dark red-violet \\
\hline BT 32 & dense & conical & 1 - 2 wings & uniform & dark red-violet \\
\hline BT 33 & very dense & funnel shaped & 1 - 2 wings & uniform & dark red-violet \\
\hline BT 34 & very dense & funnel shaped & 1 - 2 wings & uniform & dark red-violet \\
\hline BT 35 & very dense & cylindrical & absent & uniform & dark red-violet \\
\hline BT 36 & dense & cylindrical & 1 - 2 wings & uniform & dark red-violet \\
\hline BT 37 & dense & conical & 1 - 2 wings & uniform & dark red-violet \\
\hline BT 38 & very dense & funnel shaped & 1 - 2 wings & uniform & dark red-violet \\
\hline ВТ 39 & medium & conical & 1 - 2 wings & uniform & dark red-violet \\
\hline BT 40 & very dense & cylindrical & $1-2$ wings & uniform & dark red-violet \\
\hline BT 41 & very dense & cylindrical & 1 - 2 wings & uniform & dark red-violet \\
\hline BT 42 & dense & conical & 1 - 2 wings & non uniform & dark red-violet \\
\hline BT 43 & very dense & cylindrical & 1 - 2 wings & uniform & red \\
\hline BT 44 & dense & cylindrical & 1 - 2 wings & uniform & rose \\
\hline BT 45 & very dense & cylindrical & 1 - 2 wings & uniform & red \\
\hline BT 46 & very dense & cylindrical & $1-2$ wings & uniform & red \\
\hline BT 47 & very dense & funnel shaped & 1 - 2 wings & uniform & blue-black \\
\hline BT 48 & dense & funnel shaped & 1 - 2 wings & uniform & dark red-violet \\
\hline BT 49 & very dense & funnel shaped & $1-2$ wings & uniform & blue-black \\
\hline BT 50 & dense & conical & 1 - 2 wings & uniform & blue-black \\
\hline BT 51 & dense & conical & 3 - 4 wings & uniform & dark red-violet \\
\hline BT 52 & very dense & conical & $1-2$ wings & uniform & blue-black \\
\hline BT 53 & dense & conical & $1-2$ wings & uniform & dark red-violet \\
\hline BT 54 & very dense & cylindrical & 1 - 2 wings & uniform & red \\
\hline BT 55 & dense & funnel shaped & $1-2$ wings & uniform & rose \\
\hline BT 56 & very dense & funnel shaped & $1-2$ wings & uniform & dark red-violet \\
\hline BT 57 & medium & conical & 3 - 4 wings & uniform & dark red-violet \\
\hline BT 58 & very dense & conical & $1-2$ wings & uniform & blue-black \\
\hline
\end{tabular}


TABLE 2 (CONTINUED)

\begin{tabular}{|c|c|c|c|c|c|}
\hline Biotypes & (OIV 204) & (OIV 208) & (OIV 209) & (OIV 222) & (OIV 225) \\
\hline BT 59 & very dense & cylindrical & $1-2$ wings & uniform & dark red-violet \\
\hline BT 60 & dense & cylindrical & $1-2$ wings & uniform & blue-black \\
\hline BT 61 & very dense & conical & $1-2$ wings & uniform & dark red-violet \\
\hline BT 62 & medium & conical & 3 - 4 wings & uniform & dark red-violet \\
\hline BT 63 & very dense & conical & 1 - 2 wings & uniform & dark red-violet \\
\hline BT 64 & dense & funnel shaped & $1-2$ wings & uniform & blue-black \\
\hline BT 65 & medium & conical & 1 - 2 wings & uniform & blue-black \\
\hline BT 66 & very dense & cylindrical & 1 - 2 wings & uniform & blue-black \\
\hline BT 67 & very dense & funnel shaped & 3 - 4 wings & uniform & dark red-violet \\
\hline BT 68 & very dense & conical & 1 - 2 wings & uniform & dark red-violet \\
\hline BT 69 & dense & conical & 1 - 2 wings & uniform & dark red-violet \\
\hline BT 70 & very dense & conical & 1 - 2 wings & uniform & dark red-violet \\
\hline BT 71 & medium & cylindrical & 1 - 2 wings & uniform & dark red-violet \\
\hline BT 72 & very dense & conical & 1 - 2 wings & uniform & blue-black \\
\hline BT 73 & very dense & conical & 1 - 2 wings & uniform & dark red-violet \\
\hline BT 74 & dense & funnel shaped & 3 - 4 wings & uniform & dark red-violet \\
\hline BT 75 & very dense & conical & 1 - 2 wings & uniform & blue-black \\
\hline BT 76 & very dense & conical & 1 - 2 wings & uniform & blue-black \\
\hline BT 77 & dense & conical & 1 - 2 wings & uniform & dark red-violet \\
\hline BT 78 & dense & cylindrical & 1 - 2 wings & uniform & blue-black \\
\hline BT 79 & dense & funnel shaped & 1 - 2 wings & uniform & blue-black \\
\hline BT 80 & dense & conical & 3 - 4 wings & uniform & dark red-violet \\
\hline BT 81 & dense & conical & 1 - 2 wings & uniform & dark red-violet \\
\hline BT 82 & very dense & funnel shaped & 1 - 2 wings & uniform & blue-black \\
\hline BT 83 & medium & conical & 3 - 4 wings & uniform & dark red-violet \\
\hline BT 84 & dense & conical & $1-2$ wings & uniform & dark red-violet \\
\hline BT 85 & dense & cylindrical & $1-2$ wings & uniform & blue-black \\
\hline
\end{tabular}

Regarding the yield component analysis, berry weights ranged between a minimum of 1.44 grams and a maximum of 2.51 grams, detected on biotypes B44 and B8 respectively. The overall mean berry weight was 1.96 grams. Concerning the cluster parameters, the distribution of the number of clusters per vine among the biotypes varied between five and 15 , while cluster weight varied between 160 grams (biotype B31) and 614.1 grams (biotype B18). The average number of clusters per vine and the cluster weight for the whole population was 9 and $293.7 \mathrm{~kg}$ respectively. According to the coefficient of variation index, berry weight showed the least variable yield component $(\mathrm{CV}=0.11)$, whereas similar values were calculated for the number of clusters per vine and cluster weight ( 0.24 and 0.23 respectively) (Fig. 1).

As far as the data of fluorescence, texture and colorimetric analysis, a huge variability within the population of 85 Cannonau biotypes was observed for all the parameters assessed. More specifically, the FERARI index varied between 1.43 and 2.39, with an average of 2.10. The texture parameter, berry skin thickness, was characterised by a population average of $90 \mu \mathrm{m}$ and a CV of $16.2 \%$. At last, a noteworthy variability also was detected for the colorimetric coordinates $\mathrm{L}^{*}, \mathrm{a}^{*}$ and $\mathrm{b}^{*}$, which ranged between 23.92 and $37.39,2.15$ and 11.12 , and -4.97 and 9.42 respectively.

The results of the principal component analysis (PCA) performed to establish the relationships between the variables and the 85 biotypes are reported in Fig. 2 . The first two principal components explained $62 \%$ of the variability in the original data. In the PCA analysis, all variables were initially considered, but the best performance of the biotypes' discrimination analysis was obtained when using 11 of them. The variables that best separated the biotypes were the following: L*, a* and $b^{*}$ CIELab coordinates (colorimetric analysis), berry skin thickness (texture analysis), FERARI (fluorescence analysis), TSS, $\mathrm{pH}$ and titratable acidity (technological maturity), total polyphenols and total anthocyanins (phenolic maturity), and berry weight (agronomic parameter). Eight biotypes were characterised as being completely distinct from the others (Fig. 2a). The first component, explaining $46.83 \%$ of the variance, was associated with the CIELab coordinates and FERARI, pH, TSS and anthocyanins, while the second component was correlated with berry skin thickness, acidity, total polyphenols and berry weight (15.16\% of the variance). The eight biotypes identified as being highly distinct from all others were characterised by high CIELab coordinate values and titratable acidity, and low values of FERARI and TSS (Fig. 2b).

The 11 variables used to perform the PCA analysis were used in order to enhance the differentiation between the 85 biotypes to perform a cluster analysis. The dendrogram obtained using the complete linkage and the square Euclidean distance is reported in Fig. 3. Five groups were identified by cluster analysis. The first two groups (named 1 and 2) include the eight biotypes selected by PCA. Group 1 contains five biotypes and group 2 contains three biotypes. Groups 3, 4 and 5 are composed as follows: group 3 includes 34 biotypes, group 431 biotypes and group 512 biotypes. These last three groups are characterised by low CIELab coordinate values, high values of total polyphenols and 


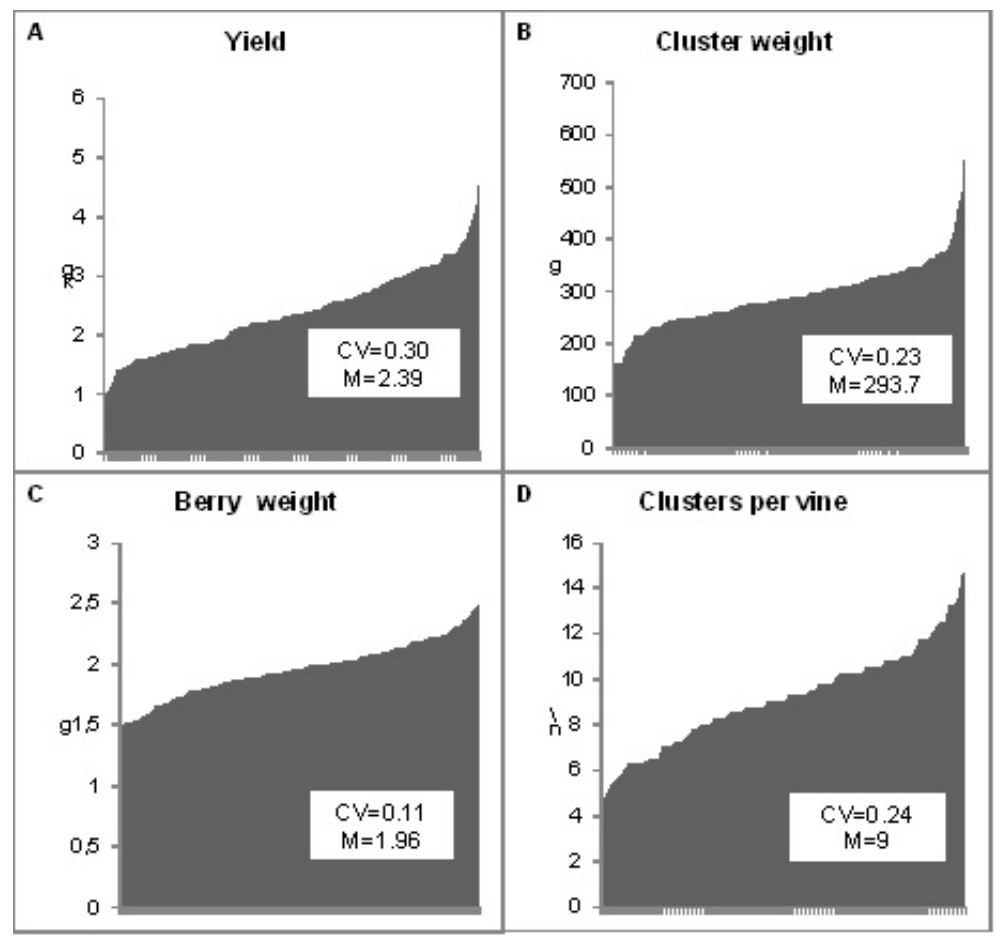

FIGURE 1

Distribution of yield (A) and its components, cluster weight (B), berry weight (C) and number of clusters per vine (D) in the Cannonau population. Coefficient of variation $(\mathrm{CV})$ and mean $(\mathrm{M})$ are reported.
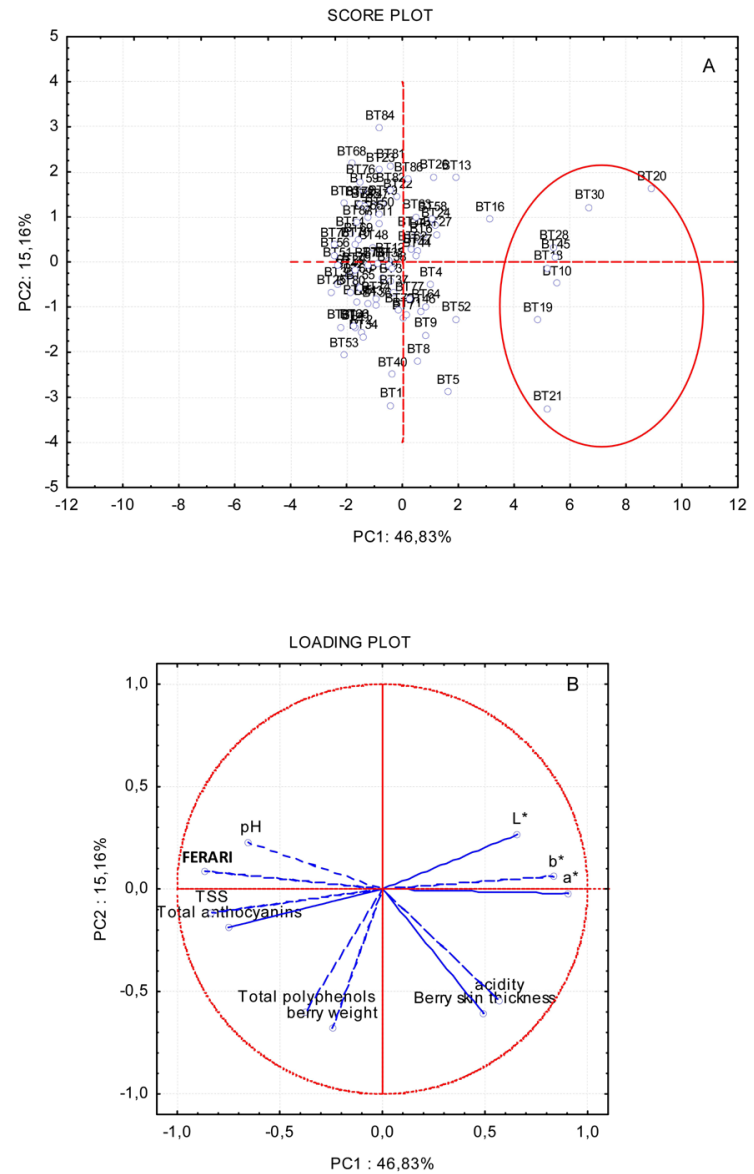

FIGURE 2

PCA score plot (a) and loading plot (b) of the 85 Cannonau biotypes, performed using the variables best able to separate the 85 biotypes. a) BT means biotype, b) TSS means total soluble solids, L* indicates lightness, a* indicates red $(+$ a) to green $(-$ a) colours, and $b^{*}$ indicates yellow $(+b)$ to blue $(-b)$ colours. 


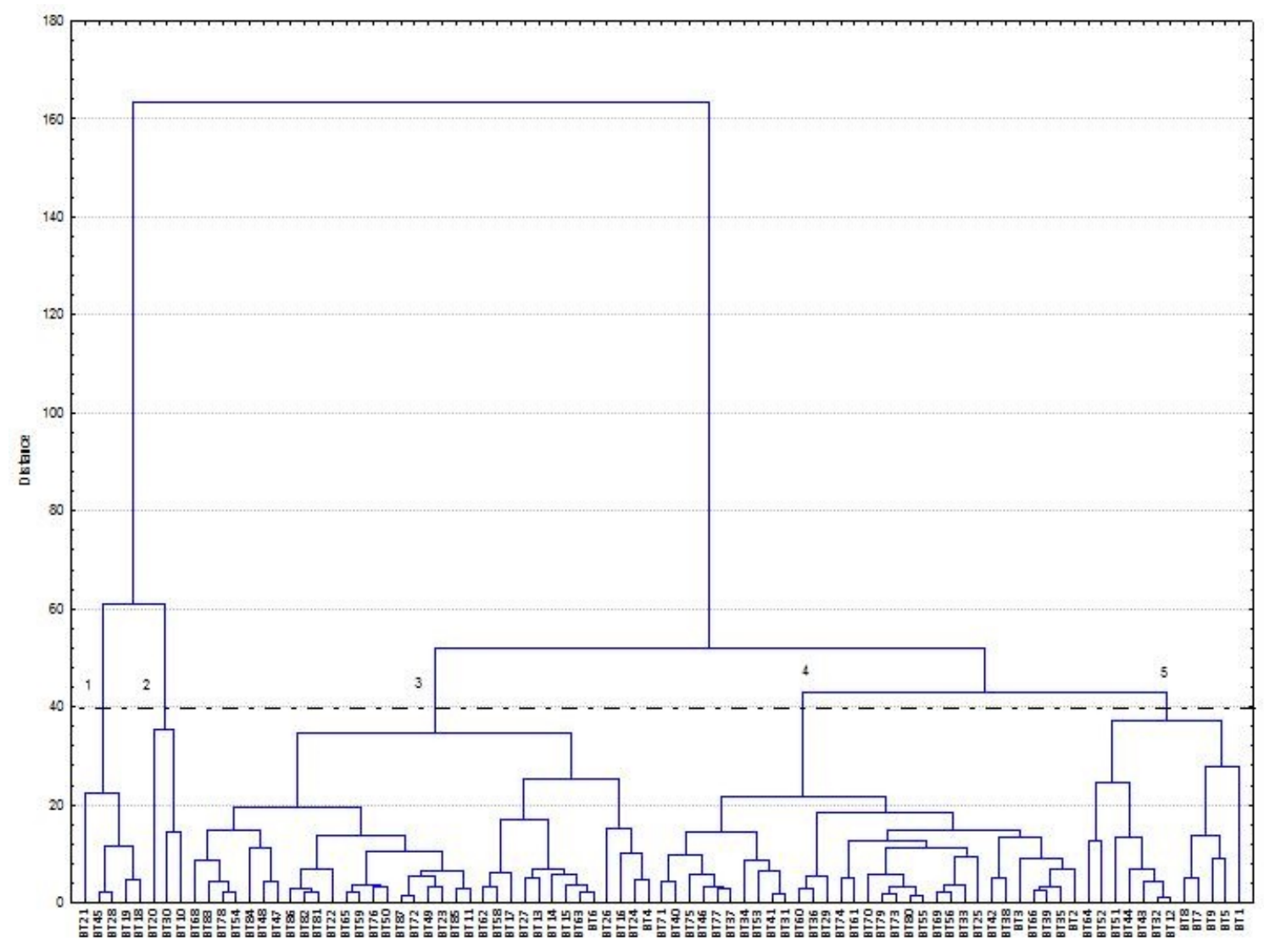

FIGURE 3

Cluster analysis of the 85 Cannonau biotypes performed with the same variables used for PCA analysis. BT means biotype.

anthocyanins, FERARI and TSS, and low values of berry skin thickness and titratable acidity. Fig. 4 summarises the differences between the different groups in relation to the colorimetric parameters (CIELab). As can be observed, the first two groups were characterised by higher values of $\mathrm{L}^{*}$, $\mathrm{a}^{*}$ and $\mathrm{b}^{*}$ colour parameters, while in groups 3,4 and 5, the $b^{*}$ parameter showed negative values. Fig. 5 reports the profiles of the five groups obtained using the normalised mean values of the following variables: berry skin thickness, total polyphenols, total anthocyanins, FERARI, berry weight, TSS, $\mathrm{pH}$ and titratable acidity. The biotypes belonging to groups 4 and 5 are richer in anthocyanins and polyphenols than the other groups, while groups 1 and 2 are characterised by a low content of total anthocyanins, low values of FERARI and a low TSS content. Table 3 reports the mean, standard deviation (SD) and coefficient of variation $(\mathrm{CV} \%)$ of each variable for each group, and the significant differences among the groups for each variable according to LSD Fisher's test.

Table 4 reports the Pearson's correlation coefficients $(\mathrm{P}<0.05)$, which quantify the relationships between the considered variables. Berry skin thickness and berry weight were not correlated with any other variable, and production per hectare was highly and positively correlated with the $\mathrm{L}^{*}$ and $\mathrm{b}^{*}$ colour parameters and with titratable acidity. The FERARI index results were highly correlated with total anthocyanins, and also positively correlated with technological maturity ( $\mathrm{pH}$ and titratable acidity); on the other hand, this index's results were negatively correlated with grape colour (CIELab system).

\section{DISCUSSION}

The present study characterised 85 Cannonau biotypes according to their ampelographic, agronomical and technological traits. The different biotypes were selected from various sites across Sardinia and then grafted and cultivated in the same vineyard in south-west Sardinia. High levels of variability were revealed for almost all of the parameters studied. For instance, five of the six primary morphological descriptors specified on the OIV Grape Descriptor List (OIV, 2001), which is used to describe grapevine varieties, were able to distinguish between the different biotypes within the cultivar.

However, the aim of the present study was to assess the variability within the Cannonau population also using new, fast and innovative techniques never used before now to describe biotypes. This new approach, which comprised non-invasive techniques such as instrumental texture analysis, fluorescence analysis and colorimetric analysis, was successfully shown to be able to separate the biotypes into distinct groups, highlighting the possibility of being an additional evaluation tool in the projects of genetic improvement in winemaking.

There are many papers in the literature dealing with the use of CIELab parameters for red wine grape evaluation during the ripening process (Rolle \& Guidoni, 2007) and for wine colour evaluation (Gil-Muñoz et al., 1997; PérezCaballero et al., 2003); yet, to our knowledge, no data are 


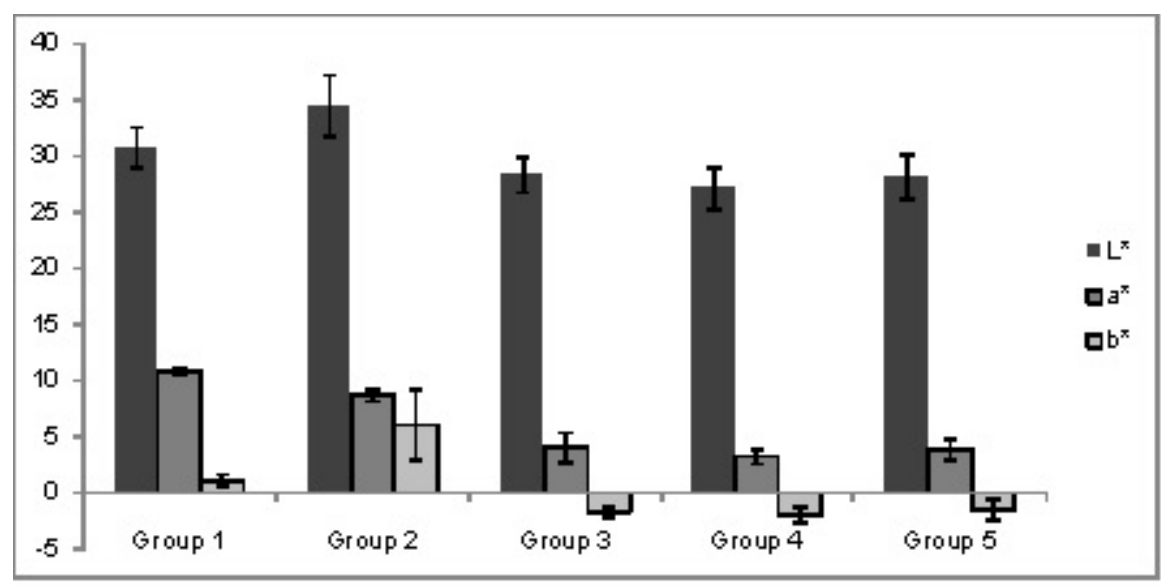

FIGURE 4

$L^{*}, a^{*}$ and $b^{*}$ CIELab parameters, obtained by tristimulus colorimetry, for the biotype groups obtained by cluster analysis. Here, the mean values for each variable obtained from the biotypes belonging to the same group are reported. Error bars indicate the standard deviation for each group and for each variable. $L^{*}$ indicates lightness, $a^{*}$ indicates red $(+a)$ to green $(-a)$ colours, and $b^{*}$ indicates yellow $(+b)$ to blue $(-b)$ colours.

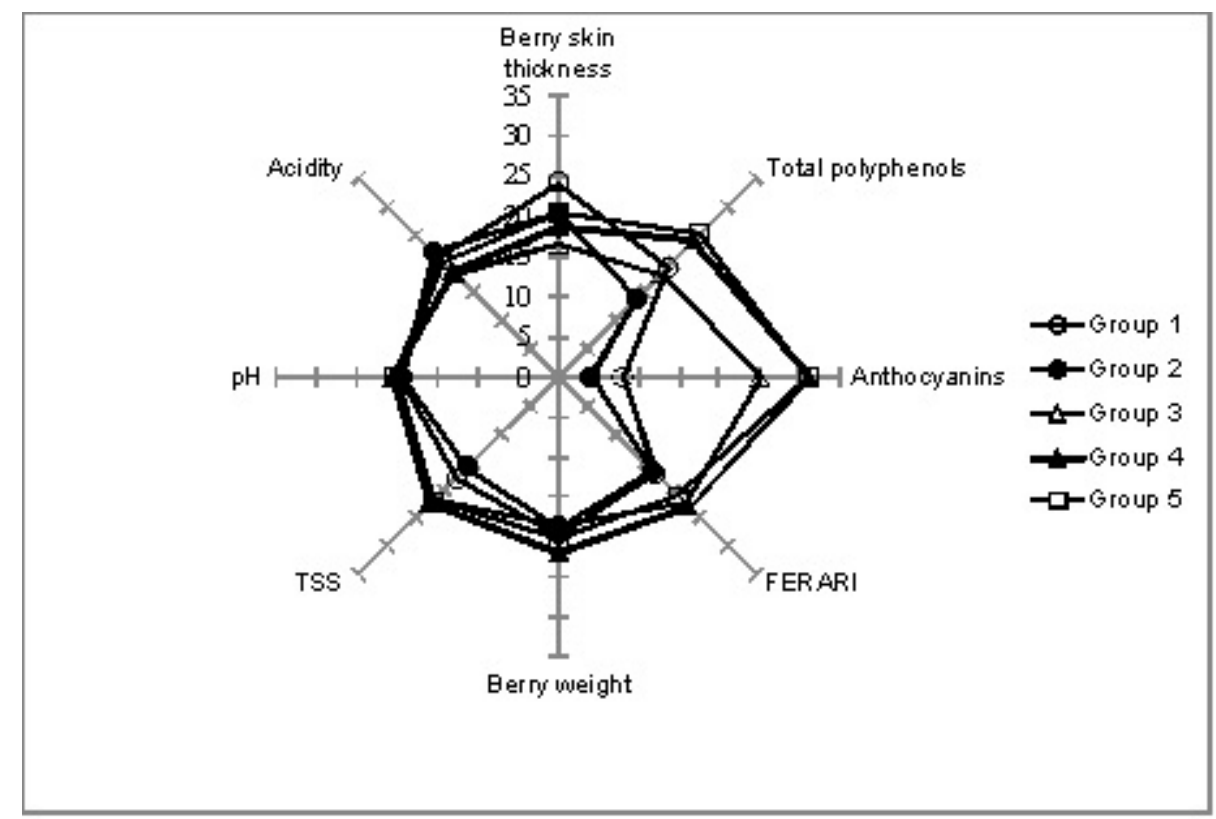

FIGURE 5

Diagram showing the profile of each Cannonau biotype group obtained by cluster analysis after normalisation of fluorescence, texture and chemical data. TSS means total soluble solids.

present in the literature on the use of CIELab parameters for discriminating between biotypes of the same variety.

PCA analysis, performed using the variables that accounted for the majority of variation between the biotypes (11 in total), revealed the relationships between the variables and the 85 biotypes and led to the identification of a group composed of eight biotypes characterised by very distinct traits compared with the remaining population (Fig. 2a). These biotypes are characterised by significant differences in berry colour and technological and phenolic maturity. In relation to colour, all of them showed high positive values for the $\mathrm{a}^{*}$ coordinate, indicating a colour between pink and red, and high positive value for the $b^{*}$ coordinate, indicating a tendency towards yellow, typical of unripe grapes (Fig. 2b).
Moreover, the $\mathrm{L}^{*}$ values were also high for these biotypes, and the values for anthocyanin content were low. This result is supported by other reports in the literature (Liang et al., 2011; Diago et al., 2013) that indicate the correlation between high $L^{*}$ values and low levels of anthocyanins; indeed, these biotypes exhibited low levels of total anthocyanins, as well as low FERARI values and low values of TSS, confirming their relative unripeness.

The relationship between the CIELab and fluorescence parameters of grapes at the time of commercial harvest was studied by Bramley et al. (2011) in order to characterise within-vineyard variations in grape berry anthocyanins, using an on-the-go sensing approach focused on anthocyanin content and using two indexes only: ANTH RG and the 


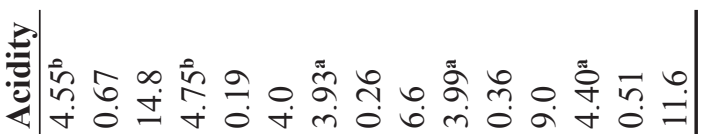

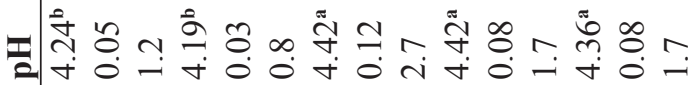

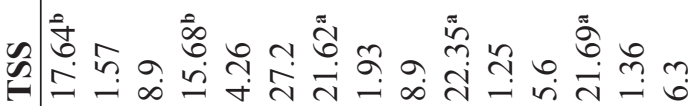

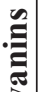

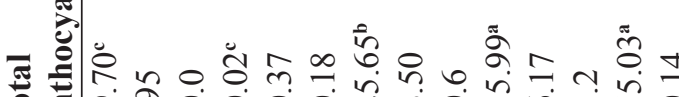

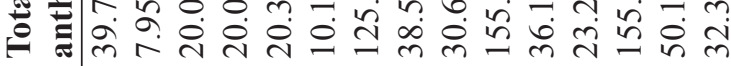

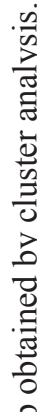

高

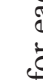

$\frac{\sqrt{3}}{2}$ 产 * * *

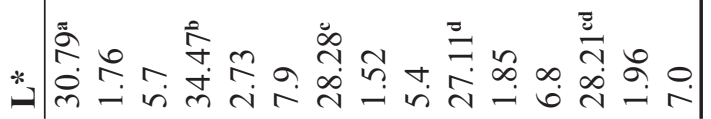
喜 ส

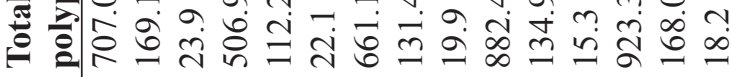

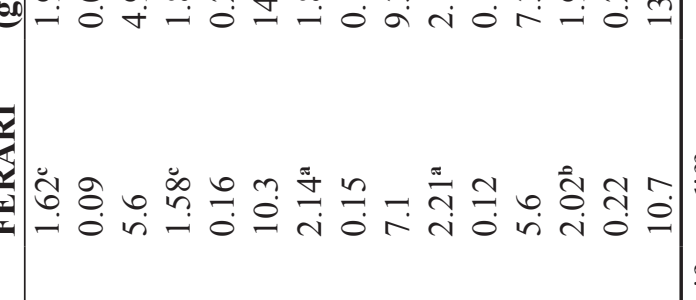
缕

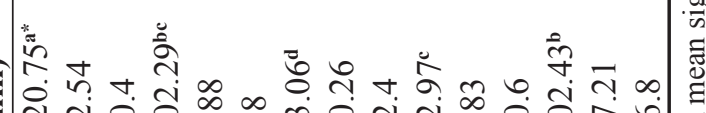

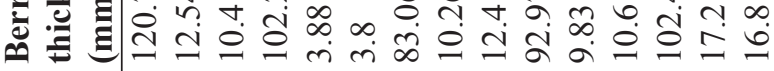

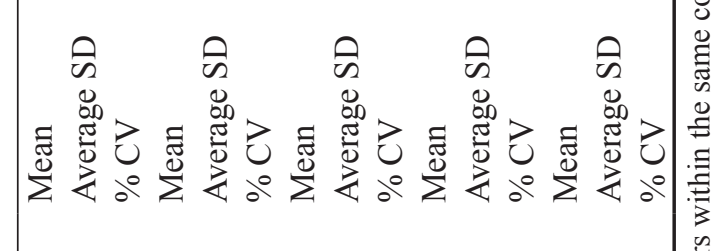

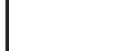

m. 西 离㠃

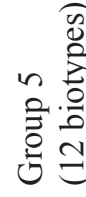

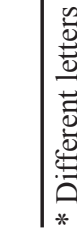

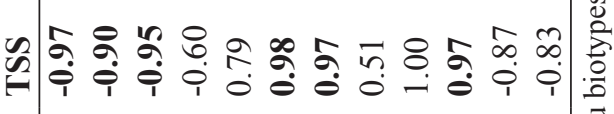

늘

$\overline{\frac{\pi}{3}}$

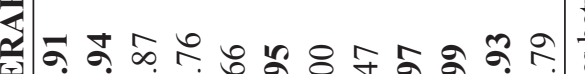

선 i i

a

.

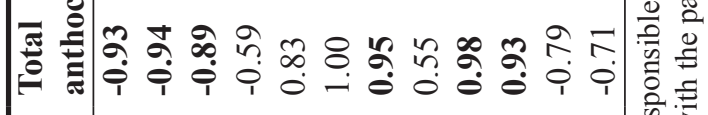

$\infty$

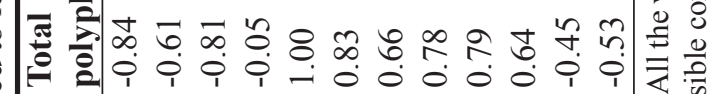

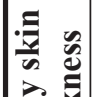

龸京

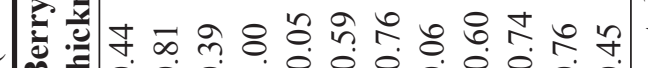
马્

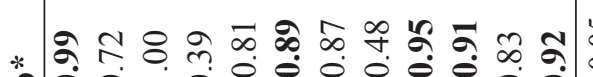

的

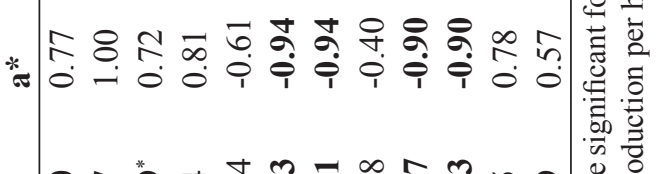
竞

*

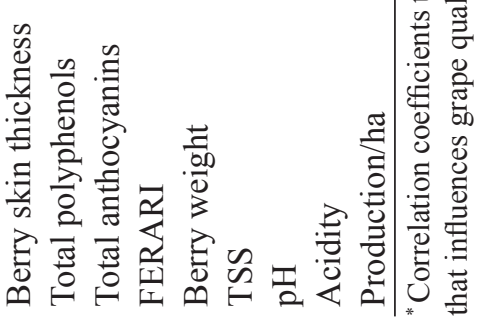

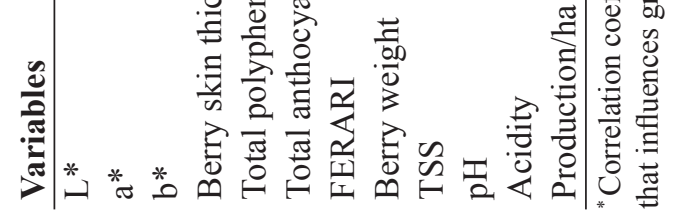


FERARI index. When the value of the ANTH RG index is high, the anthocyanin content is low (Cerovic et al., 2008; Ghozlen et al. 2010a; 2010b). ANTH_RG, when used alone, was not able to produce a clear discrimination within the Cannonau population, whereas the FERARI index significantly contributed towards separating the eight biotypes in the PCA, as reported above (Figs $2 \mathrm{a}$ and $2 \mathrm{~b}$ ). Moreover, when applying cluster analysis to the results of these methodologies, five distinct groups were identified (Fig. 3), characterised by different values of CIELab parameters, FERARI index and anthocyanins (Table 3 and Figs 4 and 5). FERARI index values showed a significant and highly positive correlation with total anthocyanins, TSS and $\mathrm{pH}$, and a significant negative correlation with $\mathrm{L}^{*}, \mathrm{a}^{*}$ (Table 4) and total acidity. The FERARI index thus represents a very good index for assaying grape anthocyanins, confirming the results of Bramley et al. (2011), and for providing a gauge of grape colour.

Instrumental texture analysis of grapes has been in use since the 1980 s to describe the changes in the mechanical properties of grape berries during ripening (Rolle et al., 2012). As is well known, berry composition at the time of harvesting is a determinant of the resulting wine quality. However, the use of instrumental texture analysis for the rapid prediction of phenolic maturity in grapes is more recent (Río Segade et al., 2008, Rolle et al., 2011); indeed, until now, no studies have addressed the potential differences in texture between biotypes belonging to the same variety, while the effectiveness of texture parameters as varietal markers has been demonstrated (Rolle et al., 2012). Although the mechanical characteristics of grapes may change from year to year due to seasonal variations (Letaief et al., 2008), berry skin thickness and the mechanical properties of seeds were evaluated for this paper at the moment of commercial harvesting to investigate the presence of possible differences between the 85 biotypes.

The mechanical properties of seeds were not able to differentiate between the biotypes, thus attention was focussed on berry skin thickness. Data obtained from the berry skin thickness analysis of the 85 Cannonau biotypes were lower than some data reported in the literature (Río Segade et al., 2008; Giacosa et al., 2013) for other varieties. In fact, cv. Cannonau is well known for its thin skin, so this variety, according to OIV code number 228 (berry: thickness of skin) of the OIV Descriptor List (2001), could be ranged between note 1 (very thin) and note 3 (thin). Many studies have investigated the correlation between berry skin thickness and anthocyanin extractability in relation to various cultivars, and the general consensus is that thinner skins produce a greater release of anthocyanins (Río Segade et al. 2008; 2011a). In this paper, only the biotypes included in the first group, characterised by low values of anthocyanins, FERARI and TSS and high values of $\mathrm{L}^{*}, \mathrm{a}^{*}$ and $\mathrm{b}^{*}$ coordinates, revealed high values for skin thickness, even though the same values were also reported for group 5, characterised by high values of TSS, anthocyanins and FERARI, suggesting that the parameter berry skin thickness is not able to differentiate between the Cannonau biotypes; hence, it was not considered a good variable for differentiating between cultivars, as also concluded by Río Segade et al. (2008). However, this result does not correspond with the data of Rolle et al.(2012), who found significant differences between the different Italian cultivars studied, and attributed the variations observed in the same cultivar to possible clonal differences. Finally, no correlations were present between berry skin thickness and the CIELab parameters, technological maturity parameters or FERARI values, suggesting that this variable, when used alone, is not useful for predicting the phenolic and/or technological maturity of grapes (Río Segade et al. 2011b).

Concerning berry weight, several papers have reported a relationship between this parameter and the other components responsible for the quality of the must, whereas others have reported that further factors, such as climatic conditions and cultivation techniques, are likely to play more significant roles in determining grape composition (Ferrer et $a l ., 2014)$. It is well known that grape variety and vintage are responsible for the differences in berry weight, and that TSS content seems to be dependent on berry weight, although a correlation was found if sugars were expressed as g/berry. In the present study we did not find any correlation between TSS, expressed in ${ }^{\circ}$ Brix, and berry weight. Thus, the present data confirm previous findings that show that total anthocyanin content is independent of berry weight (Ferrer et al., 2014). In fact, no significant correlation was found between total anthocyanins and berry weight.

In addition to berry size, grape yield is widely acknowledged as a determining factor of wine grape quality. It is generally considered that must quality decreases as the yield increases. In our study, production per hectare was positively correlated with the $\mathrm{L}^{*}$ and $\mathrm{b}^{*}$ parameters and with titratable acidity, showing that, when the production is high, the 'lightness' of the berry colour is high, which tends towards yellow, resulting in less mature grapes. This data was confirmed by grape acidity, which was significantly and positively correlated with production per hectare.

\section{CONCLUSIONS}

In our findings we observed extensive agronomical variability within the biotypes of the same Cannonau variety. Specifically, significant differences in titratable acidity and total soluble solids (TSS) were identified between the 85 biotypes, as well as different anthocyanin and polyphenol contents. Until now, fluorescence, texture and colorimetry techniques have mainly been used as a means to evaluate the best data for grape harvest, and only recently have these methodologies been used to differentiate between table and wine grape varieties. Here, for the first time, these techniques were used to evaluate variability within the Cannonau variety, in comparison with data obtained using the standard chemical analyses commonly used to evaluate the stage of grape technological and phenolic maturity. In particular, the application of fluorescence and colorimetric techniques was able to separate the biotypes into distinct groups, thereby providing a rapid and non-invasive tool for the assessment of wine grape quality. The proposed techniques could also help winemakers identify the most appropriate harvesting period for each biotype. 


\section{LITERATURE CITED}

Anderson, K., 2013. Which wine grape varieties are grown where? A global empirical picture. University of Adelaide Press, Adelaide.

Anderson, M.M., Smith, R.J., Williams, M.A. \& Wolpert, J.A., 2008. Evaluation of French and California Pinot Noir clones grown for production of sparkling wine. Am. J. Enol. Vitic. 59, 188-193.

Bahar, A., Kaplunov, T., Zutahy, A., Daus, S., Lurie, S. \& Lichter, A., 2012. Auto-fluorescence for analysis of ripening in Thompson Seedless and colour in Crimson Seedless table grapes. Aust. J. Grape Wine Res. 18, 353-359.

Battista, F., Tomasi, D., Porro, D., Caicci, F., Giacosa, S. \& Rolle, L., 2015. Winegrape berry skin thickness determination: Comparison between histological observation and texture analysis determination. Ital. J. Food Sci. 27, 136-141.

Belancic, A. \& Agosin, E., 2007. Methoxypyrazines in grapes and wines of Vitis vinifera cv. Carmenere. Am. J. Enol. Vitic. 58, 462-469.

Boso, S., Santiago, J. \& Martinez, M., 2004. Intravarietal agronomic variability in Vitis vinifera L. cv. Albarino. Am. J. Enol. Vitic. 55, 279-282.

Bramley, R.G.V., Le Moigne, M., Evain, S., Ouzman, J., Florin, L., Fadaili, E.M., Hinze, C.J. \& Cerovic, Z.G., 2011. On-the-go sensing of grape berry anthocyanins during commercial harvest: Development and prospects. Aust. J. Grape Wine Res. 17, 316-326.

Carimi, F., Mercati, F., De Michele, R., Fiore, M.C., Riccardi, P. \& Sunseri, F., 2011. Intra-varietal genetic diversity of the grapevine (Vitis vinifera L.) cultivar "Nero d'Avola" as revealed by microsatellite markers. Genet. Resour. Crop Ev. 58, 967-975.

Cerovic, C.Z., Moise, N., Agati, G., Latouche, G., Ghozlen, N.B. \& Meyer, S., 2008. New portable optical sensors for the assessment of winegrape phenolic maturity based on berry fluorescence. J. Food Comp. Anal. 21, 650-654.

Chessa, I. \& Nieddu, G., 2005. Analysis of diversity in the fruit tree genetic resources from Mediterranean island. Genet. Resour. Crop Ev. 52, 267-276.

Diago, M.P., Guadalupe, Z., Baluja, J., Millan, B. \& Tardaguila, J., 2013. Appraisal of wine color and phenols from a non-invasive grape berry fluorescence method. J. Int. Sci. Vigne Vin 47, 55-64.

Di Stefano, R. \& Cravero, M.C., 1991. The grape phenolic determination. Riv. Vitic. Enol. 49, 37-45.

Fernandes de Oliveira, A., Mercenaro, L., Del Caro, A., Pretti, L. \& Nieddu, G., 2015. Distinctive anthocyanin accumulation responses to temperature and natural UV radiation of two field-grown (Vitis vinifera L.) cultivars. Molecules 20(2), 2061-2080.

Ferrer, M., Echeverría, G. \& Carbonneau, A., 2014. Effect of berry weight and its components on the contents of sugars and anthocyanins of three varieties of Vitis vinifera L. under different water supply conditions. S. Afr. J. of Enol. Vitic. 35, 103-113.

Fidelibus, M.W., Christensen, L.P., Katayama, D.G. \& Verdenal, P.T., 2006. Yield components and fruit composition of six Chardonnay grapevine clones in the central Joaquin Valley, California. Am. J. Enol. Vitic. 57, 503506.

Ghozlen, N.B., Cerovic, C.Z., Germain, C., Toutain, S. \& Latouche, G., 2010a. Non-destructive optical monitoring of grape maturation by proximal sensing. Sensors 10: 10040-10068.

Ghozlen, N.B., Moise, N., Latouche, G., Martinon, V., Mercier, L., Besancon, E. \& Cerovic, C.Z., 2010b. Assessment of grapevine maturity using a new portable sensor: Non-destructive quantification of anthocyanins. J. Int. Sci. Vigne Vin 44, 1-8.
Giacosa, S., Torchio, F., Río Segade, S., Gaiotti, F., Tomasi, D., Lovat, L., Vincenzi, S. \& Rolle L., 2013. Physico-mechanical evaluation of the aptitude of berries of red wine grape varieties to resist the compression in carbonic maceration vinification. Int. J. Food Sci. Tech. 48, 817-825.

Gil-Muñoz, R., Gómez-Plaza, E., Martínez, A. \& López-Roca, J.M., 1997. Evolution of the CIELAB and other spectrophotometric parameters during wine fermentation. Influence of some pre and postfermentative factors. Food Res. Int. 30, 699-705.

Letaief, H., Rolle, L. \& Gerbi, V., 2008. Mechanical behavior of winegrapes under compression tests. Am. J. Enol. Vitic. 59, 323-329.

Liang, Z., Sang, M., Fan, P., Wu, B., Wang, L., Yang, S. \& Li, S., 2011. CIELAB coordinates in response to berry skin anthocyanins and their composition in Vitis. J. Food Sci. 76, 490-497.

Mannini, F., Mollo, A., Santini, D., Tragni, R. \& Marchese, E., 2011. Clone-environment interaction: Agronomic and enological performances of "Barbera" selections in two vine-growing areas of Piedmont (north-west Italy). In: Proc. 17th Intern. Symp. GiESCO, August/September, Asti and Alba, Italy. pp. $127-130$.

Meneghetti, S., Costacurta, A., Frare, E., Da Rold, G., Migliaro, D., Morreale, G., Crespan, M., Sotes, V. \& Calò, A., 2011. Clones identification and genetic characterization of Garnacha grapevine by means of different PCR-derived marker systems. Mol. Biotechnol. 48, 244-254.

Mercenaro, L., Usai, G., Tedde, N., Peretto, R. \& Nieddu, G., 2009. Evaluation of seven Vermentino selections in a Mediterranean environment. In: Proc. 16th Intern. Symp. GiESCO, July, Davis, California. pp. 449 - 453

Mulas, G., Galuffi, M.G., Pretti, L., Nieddu, G., Mercenaro, L., Tonelli, R. \& Anedda, R., 2011. NMR analysis of seven selections of Vermentino grape berry: Metabolites composition and development. J. Agric. Food Chem. 59, 793-802.

Nieddu, G., Chessa, I. \& Mercenaro, L., 2006. Primary and secondary characterization of Vermentino grape clones collection. In: Proc. 1st Intern. Symp. Environ., Identities and Mediterranean area, ISEIM, July, Corte, France. pp. $1-5$.

OIV, 1990. Recueil des méthodes internationales d'analyse des vins et des moûts. Office International de la vigne et du vin, Paris.

OIV, 2001 ( $2^{\text {nd }}$ ed). OIV descriptor list for grape varieties and Vitis species. Office international de la vigne et du vin, Paris.

Pérez-Caballero, V., Ayala, F., Echávarri, J.F. \& Negueruela, A., 2003. Proposal for a new standard OIV method for determination of chromatic characteristics of wine. Am. J. Enol. Vitic. 54, 59-62.

Río Segade, S., Giacosa, S., Gerbi, V. \& Rolle, L., 2011a. Berry skin thickness as main texture parameter to predict anthocyanin extractability in winegrapes. Food Sci. Technol. 44, 392-398.

Río Segade, S., Rolle, L., Gerbi V. \& Orriols, I., 2008. Phenolic ripeness assessment of grape skin by texture analysis. J. Food Comp. Anal. 21, 599607.

Río Segade, S., Soto Vazquez, E., Orriols, I., Giacosa S. \& Rolle, L., 2011 b. Possible use of texture characteristics of winegrapes as markers for zoning and their relationship with anthocyanin extractability index. Int. J. Food Sci. Tech. 46, 386-394.

Rolle, L. \& Guidoni, S., 2007. Color and anthocyanin evaluation of red winegrapes by CIE L*, a*, b* parameters. J. Int. Sci. Vigne Vin 41, 193-201.

Rolle, L., Gerbi, V., Schneider, A., Spanna F. \& Río Segade, S., 2011. Varietal relationship between instrumental skin hardness and climate for grapevines (Vitis vinifera L.). J. Agric. Food Chem. 59, 10624-10634.

Rolle, L., Siret, R., Río Segade, S., Maury, C., Gerbi, V. \& Jourjon, F., 2012. Instrumental texture analysis parameters as markers of table-grape and winegrape quality: A review. Am. J. Enol. Vitic. 63, 11-28. 
Vacca, V., Del Caro, A., Milella, G.G. \& Nieddu, G., 2009. Preliminary characterization of Sardinian red grape cultivars (Vitis vinifera L.) according to their phenolic potential. S. Afr. J. of Enol. Vitic. 30(2), 99-100.
Van Leeuwen, C., Roby, J.P., Alonso-Villaverde, V. \& Gindro, V., 2012. Impact of clonal variability in Vitis vinifera Cabernet franc on grape composition, wine quality, leaf blade stilbene content, and downy mildew resistance. J. Agric. Food Chem. 61, 19-24. 